\title{
Nanoscale
}

\section{Gold cluster-nanoparticle diad systems for plasmonic enhancement of photosensitization}

Cite this: Nanoscale, 2013, 5, 7855

Received 10th May 2013

Accepted 30th June 2013

DOI: $10.1039 / c 3 n r 02420 b$

\author{
Atsushi Kogo, Yukina Takahashi, $\uparrow$ Nobuyuki Sakaił and Tetsu Tatsuma*
}

Quantum-sized gold clusters are deposited on $\mathrm{TiO}_{2}$ both as a photosensitizer and catalyst, and coupled to plasmonic gold nanoparticles as a light harvesting antenna. Photocurrent enhancement was observed for $\mathrm{Au}_{25}(\mathrm{SG})_{18}$ and $\mathrm{Au}_{38}(\mathrm{SG})_{24}$ but not for $\mathrm{Au}_{102}(\mathrm{SG})_{44}(\mathrm{SG}=$ glutathione). The maximum enhancement factor of $\sim 9$ is reached at $900 \mathrm{~nm}$.

www.rsc.org/nanoscale

\section{Introduction}

Quantum-sized metal clusters (CLs), which are smaller than $2 \mathrm{~nm}$ in diameter and consist of less than 250 metal atoms, have discrete electron levels and exhibit molecular-like properties rather than bulk metals. ${ }^{1,2}$ For example, metal CLs exhibit optical absorption from ultraviolet to near infrared regions, ${ }^{3,4}$ fluorescence $^{5,6}$ and two photon absorption ${ }^{7}$ based on electron transition between the discrete electron levels. Metal CLs supported on an appropriate substrate also work as effective catalysts $^{8}$ and electrocatalysts. ${ }^{9}$

Our recent studies have shown that metal CLs serve as a photosensitizer of $\mathrm{TiO}_{2}$ (Fig. 1a) as do some ruthenium dyes. ${ }^{10,11}$ Metal CL-modified $\mathrm{TiO}_{2}$ exhibits photovoltaic ${ }^{11-13}$ and photocatalytic ${ }^{14}$ properties in response to visible and near infrared light. The metal CLs have a great advantage as a sensitizer; their HOMOLUMO energy gap and absorption wavelength can be tuned by changing their core size.,15 Moreover, efficient redox reactions can be expected if the catalytic and electrocatalytic properties of the CLs are combined with their capability as a sensitizer.

Despite the high internal quantum efficiency of $\sim 60 \%$ for $\mathrm{Au}$ CL-modified $\mathrm{TiO}_{2}$, their external quantum efficiency (incident photon-to-electron conversion efficiency, IPCE) has been as low as $\sim 10 \% .{ }^{12}$ This is due to the low photoabsorption efficiency of the Au CLs (molar absorption coefficient $\varepsilon \sim 10^{4} \mathrm{M}^{-1} \mathrm{~cm}^{-1}$ at $670 \mathrm{~nm}$ ). ${ }^{3}$ Although the photoabsorption improves as the amount of the Au CLs adsorbed on porous $\mathrm{TiO}_{2}$ increases, the CLs, which are relatively bulky compared to ruthenium dyes, block the mass transfer of a redox species in the nanopores and the internal resistance would be increased.

Institute of Industrial Science, The University of Tokyo, 4-6-1 Komaba, Meguro-ku, Tokyo 153-8505, Japan. E-mail: tatsuma@iis.u-tokyo.ac.jp; Fax: +81-3-5452-6338; Tel: $+81-3-5452-6336$

$\uparrow$ Present address: Department of Applied Chemistry, Faculty of Engineering, Kyushu University, 744 Moto-oka, Nishi-ku, Fukuoka 819-0395, Japan.

\$ Present address: International Center for Materials Nanoarchitectonics, National Institute for Materials Science, 1-1 Namiki, Tsukuba, Ibaraki 305-0044, Japan.
In the present work, we couple Au CLs to gold nanoparticles (Au NPs) as a light-harvesting antenna, in order to achieve both high internal quantum efficiency and high photoabsorption. Plasmonic metal NPs, which are larger than $3 \mathrm{~nm}$ in diameter, exhibit intense light absorption at a specific wavelength based on localized surface plasmon resonance (LSPR) and generate an optical near field (localized oscillating electric field) around their surface, which in turn excites dyes and semiconductors in the vicinity. Their absorption cross-section usually exceeds their geometrical cross-section ${ }^{16}$ and the lifetime of the near field is much longer than the time for photons to pass by a NP. Photons are thus confined in the vicinity of the NPs and photoabsorption of the dyes and semiconductors around the NPs is enhanced. Therefore, the plasmonic metal NPs have been applied to photoantennas for surface enhanced Raman spectroscopy (SERS) ${ }^{17}$ enhanced fluorescence, ${ }^{18}$ photocatalysis ${ }^{19-22}$ and photovoltaics. ${ }^{23-25}$

Here we report the Au CL-NP diad systems with photocurrents enhanced by a factor of $\sim 6$ and $\sim 9$ under visible and near
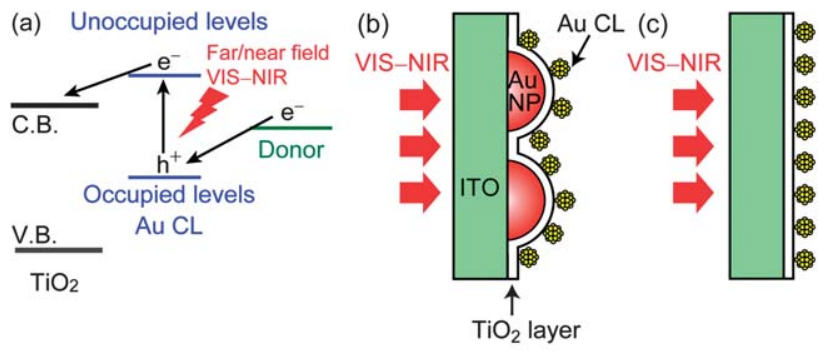

(d)
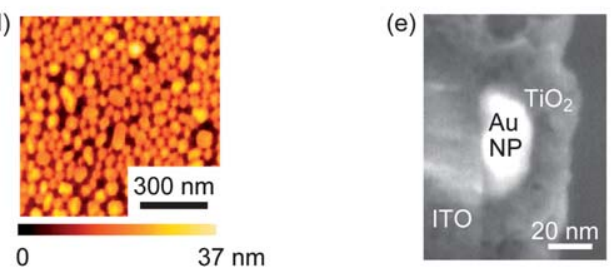

Fig. 1 (a) Photocurrent generation at the $\mathrm{Au} \mathrm{CL}$-modified $\mathrm{TiO}_{2}$. Schematic illustration of (b) ITO/Au NP/TiO $/ 2 / A u C L$ and (c) ITO/TiO $2 / A u$ CL electrodes. (d) An AFM image of Au NPs on ITO and (e) a SEM cross-sectional image of an ITO/Au $\mathrm{NP} / \mathrm{TiO}_{2} / \mathrm{Au} \mathrm{CL}$ electrode. 
infrared light, respectively. We also found that the enhancement factor is increased as the CL size decreases.

The diad systems with high internal quantum efficiency and intense light absorption, which are characteristic of Au CLs and $\mathrm{Au}$ NPs, respectively, would lead to the development of more sophisticated photofunctional devices and materials than conventional CL-based photovoltaics ${ }^{11-13}$ and photocatalysts ${ }^{14}$ and plasmonic NP-based photovoltaic, ${ }^{26-28}$ photocatalytic, ${ }^{26,29,30}$ photochromic $^{31-34}$ and organic photomorphing ${ }^{35}$ materials.

\section{Experimental}

\section{Synthesis of $\mathrm{Au}_{25}(\mathrm{SG})_{18}$}

$\mathrm{Au}_{25}(\mathrm{SG})_{18}(\mathrm{GSH}=$ glutathione $)$ was synthesized according to the literature ${ }^{3,36}$ with some modifications. GSH $(1 \mathrm{mmol})$ was added to a methanol solution of $\mathrm{HAuCl}_{4}(5 \mathrm{mM}, 50 \mathrm{~mL})$. The solution was cooled at $4{ }^{\circ} \mathrm{C}$ for $30 \mathrm{~min}$ and an ice-cold aqueous $\mathrm{NaBH}_{4}(0.2 \mathrm{M}, 12.5 \mathrm{~mL})$ was added to the solution under vigorous stirring and aged for $1 \mathrm{~h}$. The precipitate formed was collected by centrifugation $(3000 g, 5 \mathrm{~min})$ and thoroughly rinsed with methanol and dried in a vacuum at room temperature to obtain a mixture of Au CLs. The mixture (5 mg) was dissolved in an aqueous solution (7 mL) containing $\mathrm{GSH}$ (130.7 mg) and stirred at $55{ }^{\circ} \mathrm{C}$ under air bubbling for $9 \mathrm{~h}$ to obtain $\mathrm{Au}_{25}(\mathrm{SG})_{18}$. Excess GSH was removed by using a dialysis membrane (MWCO 8000, Fisher Scientific) under gentle stirring at $<10{ }^{\circ} \mathrm{C}$ for $12 \mathrm{~h}$. The precipitate formed was removed with a filter (pore size $0.2 \mu \mathrm{m}$ ).

An aqueous solution of the synthesized $\mathrm{Au}_{25}(\mathrm{SG})_{18}$ exhibits three absorption peaks at $1.84 \mathrm{eV}(674 \mathrm{~nm}), 2.75 \mathrm{eV}(451 \mathrm{~nm})$, and $3.86 \mathrm{eV}(321 \mathrm{~nm})$ and an absorption onset at $1.3 \mathrm{eV}(950 \mathrm{~nm})$ (Fig. 2b). These features are in good agreement with those of $\mathrm{Au}_{25}(\mathrm{SR})_{18}$ reported elsewhere..$^{3,36-39}$

\section{Synthesis of $\mathrm{Au}_{38}(\mathrm{SG})_{24}$ and $\mathrm{Au}_{102}(\mathrm{SG})_{44}$}

$\mathrm{Au}_{38}(\mathrm{SG})_{24}$ and $\mathrm{Au}_{102}(\mathrm{SG})_{44}$ were synthesized and separated according to our previous report. ${ }^{13} \mathrm{GSH}(0.8 \mathrm{mmol})$ was added to an ice-cold aqueous solution of $\mathrm{HAuCl}_{4}(5 \mathrm{mM}, 40 \mathrm{~mL})$ and stirred for $30 \mathrm{~min}$. An ice-cold aqueous $\mathrm{NaBH}_{4}(0.2 \mathrm{M}, 10 \mathrm{~mL})$ was added under vigorous stirring and aged for $12 \mathrm{~h}$ at room temperature. The solution was divided into four aliquots and each was added dropwise to methanol $(18.75 \mathrm{~mL})$. The precipitate formed was collected by centrifugation (13 000g, $10 \mathrm{~min})$ and thoroughly rinsed with methanol and dried in a vacuum at room temperature to obtain a mixture of Au CLS.

The mixture ( $\sim 10 \mathrm{mg}$ ) was dissolved in $1 \mathrm{~mL}$ aqueous glycerin ( 5 vol\%) and separated by electrophoresis with a $16-26 \%$ gradient polyacrylamide gel under a bias voltage of $150 \mathrm{~V}$ in an ice-cold bath for $10 \mathrm{~h}^{40}$ The bands of $\mathrm{Au}_{38}(\mathrm{SG})_{24}$ (migration distance: $68 \mathrm{~mm}$ ) and $\mathrm{Au}_{102}(\mathrm{SG})_{44}$ (migration distance: $56 \mathrm{~mm}$ ) (Fig. 2a) were cut out of the gel and immersed in pure water $(2 \mathrm{~mL})$ in a refrigerator overnight or longer to extract the Au CLs. The obtained CL solutions were filtered (pore size, $0.2 \mu \mathrm{m}$ ) to remove the gel.

An aqueous solution of the synthesized $\mathrm{Au}_{38}(\mathrm{SG})_{24}$ is characterized by five distinct absorption peaks at $1.20 \mathrm{eV}(1033 \mathrm{~nm})$, (a)

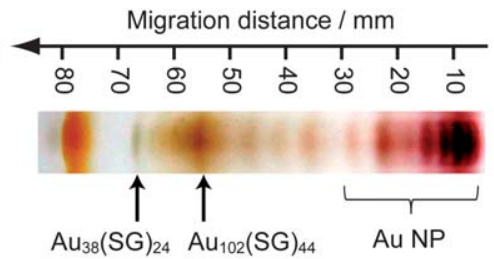

(b)
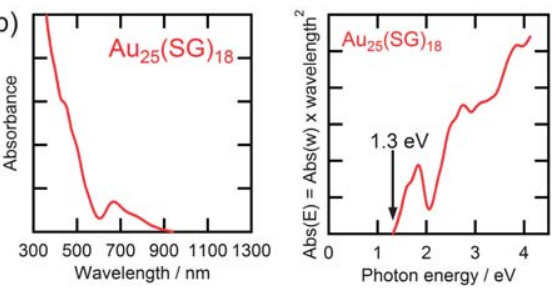

(c)
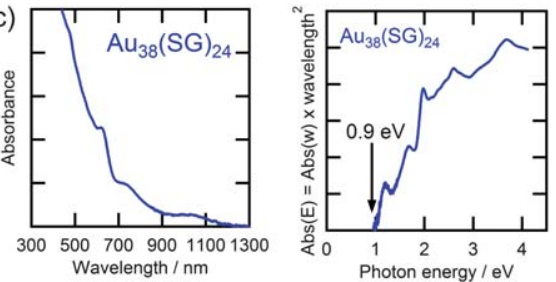

(d)
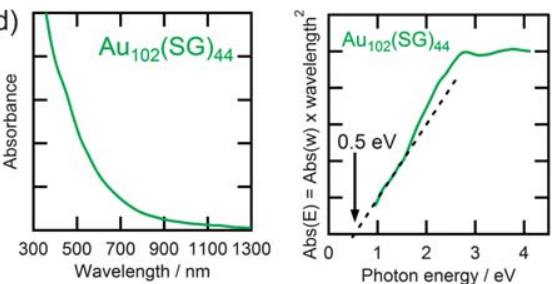

Fig. 2 (a) Electrophoretic pattern of $\mathrm{Au}_{38}(\mathrm{SG})_{24}$ and $\mathrm{Au}_{102}(\mathrm{SG})_{44}$. Absorption spectra of (b) $A_{25}(\mathrm{SG})_{18}$ (c) $\mathrm{Au}_{38}(\mathrm{SG})_{24}$ and (d) $\mathrm{Au}_{102}(\mathrm{SG})_{44}$.

$1.69 \mathrm{eV}$ (734 nm), $1.98 \mathrm{eV}$ (626 nm), $2.60 \mathrm{eV}$ (477 nm), and 3.69 $\mathrm{eV}(336 \mathrm{~nm})$ and the absorption onset at $0.9 \mathrm{eV}(1380 \mathrm{~nm})$ (Fig. 2c), which correspond to the features of $\mathrm{Au}_{38}(\mathrm{SR})_{24}$ described in previous reports. ${ }^{39,41-44}$ Two weak absorption peaks at $2.78 \mathrm{eV}(446 \mathrm{~nm})$ and $3.79 \mathrm{eV}(327 \mathrm{~nm})$ and an absorption onset at $0.5 \mathrm{eV}(2480 \mathrm{~nm})$ are observed for the synthesized $\mathrm{Au}_{102}$ (SG) ${ }_{44}$ (Fig. 2d). These characteristics are close to those for $\mathrm{Au}_{102}(\mathrm{SR})_{44}$ reported elsewhere. ${ }^{39,45,46}$ These assignments were supported by the electrophoretic migration distance. ${ }^{13}$

\section{Fabrication of ITO/Au NP/TiO $/ 2 / \mathrm{Au}$ CL electrodes}

We fabricated two-dimensional ITO/Au NP/TiO $/ 2 / \mathrm{Au} \mathrm{CL}(\mathrm{NP}=$ nanoparticle) and $\mathrm{ITO} / \mathrm{TiO}_{2} / \mathrm{Au} \mathrm{CL}$ electrodes (Fig. 1b and c) as follows. A thin Au film ( $\sim 10 \mathrm{~nm}$ thick) was vapor-deposited on a smooth ITO (indium tin oxide)-coated glass plate (Kuramoto) with vacuum deposition equipment (VPC-260F, ULVAC). The substrate was heated at $500{ }^{\circ} \mathrm{C}$ for $1 \mathrm{~h}$ to convert the $\mathrm{Au}$ film to Au NPs (Fig. 1d). The average width and height were estimated to be $42.3 \pm 17.6 \mathrm{~nm}$ and $14.6 \pm 5.4 \mathrm{~nm}$, respectively, by atomic force microscopy (AFM, NanoNavi Station, Hitachi High-Tech Science). The surface coverage of Au NPs was estimated to be 2.5 $\times 10^{10}$ particles per $\mathrm{cm}^{2}$. The ITO surface with the Au NPs and a 
bare ITO surface were coated with thin $\mathrm{TiO}_{2}$ films prepared by a spray pyrolysis method ${ }^{4-49}$ from a 2-propanol solution of titanium diisopropoxide bis(acetylacetonate) (spray pressure was $0.12 \mathrm{MPa}$, spray time was $1 \mathrm{~s}$, and calcined at $500{ }^{\circ} \mathrm{C}$ for $30 \mathrm{~min}$ ). The thickness was measured by scanning electron microscopy (SEM, JSM-7500FA, JEOL) to be 3-100 nm for the $\mathrm{TiO}_{2}$ films prepared from the $0.045-0.374 \mathrm{M}$ solution with spraying for 1 or 3 times. The deviation for the thickness of the $\mathrm{TiO}_{2}$ thin films prepared by this method m,49 $^{\mathbf{4}, 4}$ is about $30 \%$.

A solution of $\mathrm{Au}$ CLs was cast on the ITO/Au NP/TiO 2 and ITO/TiO 2 electrodes and left for $2 \mathrm{~h}$ followed by thorough rinsing with pure water and drying under airflow. GSH-protected $\mathrm{Au}$ CLs are electrostatically bound to the anatase $\mathrm{TiO}_{2}$ surface via their carboxyl groups at $\mathrm{pH} 2$ to $6 .{ }^{11}$ The $\mathrm{pH}$ values of the $\mathrm{Au}_{38}$ and $\mathrm{Au}_{102}$ solutions were adjusted to 5 with acetic acid. In the case of $\mathrm{Au}_{25}(\mathrm{SG})_{18}$, acetic acid was not added because the $\mathrm{pH}$ value of the as-prepared solution was 3.3. The concentration of the $\mathrm{Au}_{25}(\mathrm{SG})_{18}$ solution was $\sim 2 \times 10^{-5} \mathrm{M}$ (estimated with a molar extinction coefficient of $8.8 \times 10^{3} \mathrm{M}^{-1} \mathrm{~cm}^{-1}$ at $670 \mathrm{~nm}^{3}$ ). The absorbances of $\mathrm{Au}_{38}(\mathrm{SG})_{24}$ and $\mathrm{Au}_{102}(\mathrm{SG})_{44}$ solutions were $\sim 0.4$ and $\sim 1.8$ at $300 \mathrm{~nm}$, respectively. Absorption spectra of the solutions and electrodes were measured with a spectrophotometer (V-670, JASCO). Spatial distributions of the electric field around the Au NPs were calculated on the basis of a finitedifference time-domain (FDTD) method via FDTD Solutions (Lumerical Solutions).

\section{Photoelectrochemical measurements}

Two-electrode thin layer cells were constructed as follows: a HIMILAN film (50 $\mu \mathrm{m}$ thick, DuPont-Mitsui Polychemicals) with a $0.25 \mathrm{~cm}^{2}$ or $0.20 \mathrm{~cm}^{2}$ window was sandwiched between the ITO/Au NP/TiO $/$ /Au CL or ITO/TiO $/ 2 / \mathrm{Au} \mathrm{CL}$ working electrode and a Pt-coated ITO counter electrode. The interspace between the two electrodes was filled with acetonitrile containing a $0.1 \mathrm{M}$ electron donor and $0.1 \mathrm{M}$ tetra- $n$-butylammonium perchlorate, which was deaerated by $\mathrm{N}_{2}$. Lithium iodide or hydroquinone was employed as an electron donor. The cell was irradiated from the back of the working electrode with monochromatic light $\left(6 \times 10^{15}\right.$ photons per $\mathrm{cm}^{2}$ per $\mathrm{s}$, full width at half maximum (fwhm) $=10 \mathrm{~nm}$ ) using a $100 \mathrm{~W}$ Xe lamp (LAX-102, Asahi Spectra) through a bandpass filter (Asahi Spectra) and shortcircuit photocurrents were measured with a potentiostat (1280C, Solartron).

\section{Quantitation of the amounts of adsorbed Au CLS}

$0.05 \mathrm{M} \mathrm{NaOH}$ aqueous solution ( $\mathrm{pH}$ 12) was cast on the surface of the ITO/Au NP/TiO $/ \mathrm{Au} \mathrm{CL}$ or ITO/TiO $/ \mathrm{Au} \mathrm{CL}$ electrode and left for $4 \mathrm{~h}$. The amount of the Au CLs desorbed from the electrode into the solution was determined by inductively coupled plasma mass spectrometry (SPQ9000, Hitachi HighTech Science).

\section{Results and discussion}

In this work we prepared two-dimensional ${ }^{48-51} \mathrm{ITO} / \mathrm{Au} \mathrm{NP} / \mathrm{TiO}_{2} / \mathrm{Au}$ CL electrodes (Fig. $1 \mathrm{~b}$ and e) to allow control of the CL-NP spacing by changing the $\mathrm{TiO}_{2}$ thickness. If we use a three dimensional and nanoporous system, which gives higher photocurrents, effects of the spacing and CL size cannot be separated from effects of electron and ion transport. The ITO/Au $\mathrm{NP} / \mathrm{TiO}_{2} / \mathrm{Au}_{25}$ electrodes exhibited larger extinction (= absorption + scattering) than the electrodes without Au NPs (Fig. 1c) in the wavelength range $>600 \mathrm{~nm}$ due to LSPR of Au NPs (Fig. 3a). The spectrum of the ITO/TiO $/ \mathrm{Au}_{25}$ does not agree with that of $\mathrm{a} \mathrm{Au}_{25}$ aqueous solution (Fig. 2b) since an interference effect of the ITO and $\mathrm{TiO}_{2}$ layers is more significant than the absorption of $\mathrm{Au}_{25}$.

Consistent with our previous report, ${ }^{11}$ the $\mathrm{Au}_{25}$-modified $\mathrm{TiO}_{2}$ electrode generated stable anodic photocurrents in response to visible and near infrared light in the presence of hydroquinone as an electron donor. The photocurrent action spectra for the electrodes with a $6 \mathrm{~nm}$ thick $\mathrm{TiO}_{2}$ layer are shown
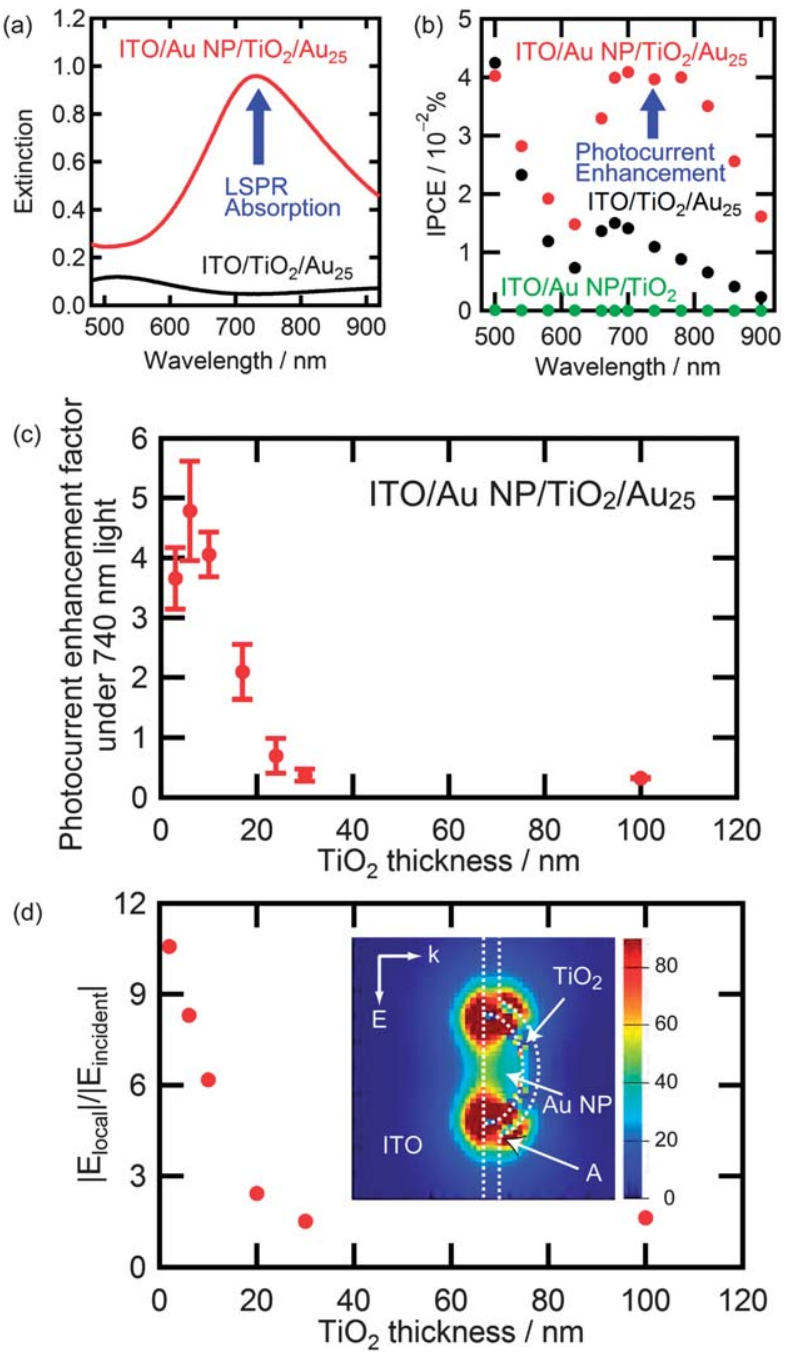

Fig. 3 (a) Absorption spectra and (b) photocurrent action spectra in the presence of hydroquinone $(0.5 \mathrm{M})$ for ITO/Au NP/TiO $2(6 \mathrm{~nm}) / \mathrm{Au}_{25}, \mathrm{ITO} / \mathrm{TiO}_{2}(6 \mathrm{~nm}) /$ $\mathrm{Au}_{25}$ and ITO/Au NP/TiO $(6 \mathrm{~nm})$ electrodes. (c) Photocurrent enhancement factor under $740 \mathrm{~nm}$ light and (d) the maximum localized electric field intensity at the $\mathrm{TiO}_{2}$ surface (point A) calculated by a FDTD method, both plotted against the $\mathrm{TiO}_{2}$ thickness. ((d), inset) Electric field distribution for a model with $6 \mathrm{~nm}$ thick $\mathrm{TiO}_{2}$ under $843 \mathrm{~nm}$ light. 
in Fig. 3b. The action spectrum of the ITO/TiO $/ \mathrm{Au}_{25}$ electrode (Fig. 3b) is in good agreement with the extinction spectrum of aqueous $\mathrm{Au}_{25}$ (Fig. 2b). This suggests that the photocurrents generate on the basis of electron injection from $\mathrm{Au}_{25}$ to $\mathrm{TiO}_{2}$ (Fig. 1a). ${ }^{11}$ On the other hand, the ITO/Au NP/TiO $2 / \mathrm{Au}_{25}$ electrode exhibited 2-9 times as large photocurrents as that without $\mathrm{Au}$ NPs at 600-900 nm (Fig. 3b), at which the Au NPs exhibit intense LSPR. Ratios of the number of $\mathrm{Au}_{25}$ CLs on the electrode with Au NPs to that without Au NPs were evaluated to be $<1.4$ so that we can conclude that the photocurrent enhancement is not due to the difference in the amount of the adsorbed $\mathrm{Au}_{25}$ on the two electrodes. At wavelengths below $600 \mathrm{~nm}$, where LSPR is weak or absent, the enhancement factor (e.g. 1.3 at $540 \mathrm{~nm}$ ) was close to the ratio of the number of adsorbed CLs. Incidentally, photocurrents of ITO/Au NP/TiO 2 electrodes were negligibly small (Fig. 3b). If these currents are increased by Au CL, the photocurrents should be cathodic, although the Au CL-NP diad system exhibits anodic photocurrents as described above. These results suggest that the photocurrents are enhanced by the plasmonic Au NPs.

If the enhancement was induced by LSPR of Au NPs, the enhancement factor should increase as the spacing between the NP and the photosensitizer decreases, because the plasmonic near field intensifies. ${ }^{19,48-52}$ When the spacing becomes too small, however, the enhancement becomes less significant. ${ }^{19,48,49,51,52}$ So we investigated the dependence of the photocurrent enhancement on the CL-NP spacing by controlling the $\mathrm{TiO}_{2}$ thickness (Fig. 3c). When the spacing was $30 \mathrm{~nm}$ or larger, the photocurrents in the presence of $\mathrm{Au}$ NPs were lower than those in the absence of the NPs. This negative effect is explained in terms of a screening effect; the extinction of NPs reduces the number of photons reaching CLs. On the other hand, when the spacing was shorter than $20 \mathrm{~nm}$, the photocurrents were enhanced by the Au NPs; a positive effect exceeded the negative screening effect. The maximum enhancement factor was reached at $6 \mathrm{~nm}$ and seemed to decrease at the shorter spacing. These results indicate that the positive enhancement effect is due to the plasmonic near field.

We also carried out finite-difference time domain (FDTD) calculations to simulate the electric field distribution for an oblate $\mathrm{Au}$ hemisphere ( $42 \mathrm{~nm}$ wide and $15 \mathrm{~nm}$ high) coated with $6 \mathrm{~nm}$ thick $\mathrm{TiO}_{2}$ (Fig. 3d, inset). In Fig. 3d, the electric field intensity at point A (indicated by the arrow in the inset) at the wavelength which gives the highest intensity is plotted against the $\mathrm{TiO}_{2}$ thickness. The intensity increases as the $\mathrm{TiO}_{2}$ thickness decreases. This behavior corresponds to that of the photocurrent enhancement in the $\mathrm{TiO}_{2}$ thickness range of $\geq 10$ nm (Fig. 3c). However, the photocurrent enhancement saturates or decreases when the thickness is $<10 \mathrm{~nm}$, although the electric field intensity still increases. Such suppression of enhancement is often observed for the plasmonic enhancement of fluorescence, ${ }^{52}$ photocatalysis ${ }^{19}$ and photocurrents of dye-sensitized solar cells. ${ }^{\mathbf{4 8 , 4 9 , 5 1}}$ In those reports, the suppression is explained in terms of energy transfer from dyes or semiconductor nanoparticles to metal NPs, which is accelerated when the spacing between them is small enough. The energy transfer should also take place in the present system, since the bandgap of $\mathrm{TiO}_{2}$ $(\sim 3.2 \mathrm{eV})$ is sufficiently larger than the energy range examined $(<2.5 \mathrm{eV})$ and $\mathrm{TiO}_{2}$ cannot trap the energy.

We also employed $\mathrm{Au}_{38}$ and $\mathrm{Au}_{102}$. Their HOMO potentials are too negative to receive electrons from hydroquinone. ${ }^{13} \mathrm{We}$ therefore used $\mathrm{I}^{-}$as an electron donor. We have previously proven that $\mathrm{TiO}_{2}$ modified with those CLs exhibits stable photocurrents in the presence of $\mathrm{I}^{-}$and that ligand exchange and etching of the CLs by $\mathrm{I}^{-}$are negligible during the photoelectrochemical measurements under deaerated conditions, on the basis of stable photocurrents and absorption spectra. ${ }^{13}$ All $\mathrm{Au}$ CL-sensitized $\mathrm{TiO}_{2}$ electrodes generated photocurrents under 500-900 nm monochromatic light (Fig. 4a-c, black symbols). The action spectrum of the ITO/TiO $/ \mathrm{Au}_{38}$ electrode (Fig. 4b) is rather featureless in comparison with the absorption spectrum of $\mathrm{a} \mathrm{Au}_{38}$ aqueous solution (Fig. 2c). This is because the absorption spectrum consists of many different electron transitions from HOMO-2, HOMO-1 and HOMO to LUMO, LUMO+1, LUMO+2 and LUMO+3 (ref. 53) and the contribution of each transition to the photocurrent is not the same.

In the case of $\mathrm{Au}_{25}$ (Fig. 4a), the $\mathrm{Au}$ NPs enhanced the photocurrents in the wavelength range of $600-900 \mathrm{~nm}$, as in the system with hydroquinone (Fig. 3b). $\mathrm{Au}_{38}$-sensitized currents were also enhanced by Au NPs, and the enhancement factor $(2.3 \pm 0.6$ at $740 \mathrm{~nm}$, Fig. 4b) was slightly smaller than that for $\mathrm{Au}_{25}(2.9 \pm 0.5)$. When $\mathrm{Au}_{102}$ was employed, however, the photocurrents were suppressed by Au NPs (Fig. 4c). We obtained similar results for $\mathrm{TiO}_{2}$ layers with different thicknesses (3-10 nm). Since the electric field intensity at the $\mathrm{TiO}_{2}$ surface does not depend on the CL size, the decrease in the enhancement factor with increasing CL size (Fig. 4d) is ascribed to accelerated back energy transfer from $\mathrm{Au}$ CLs to NPs. The energy transfer is based on the dipole-dipole interaction between a NP and a CL. Since the interaction becomes stronger as the dipole moment increases, a larger CL should be easier to transfer energy to a NP. Actually, energy transfer from
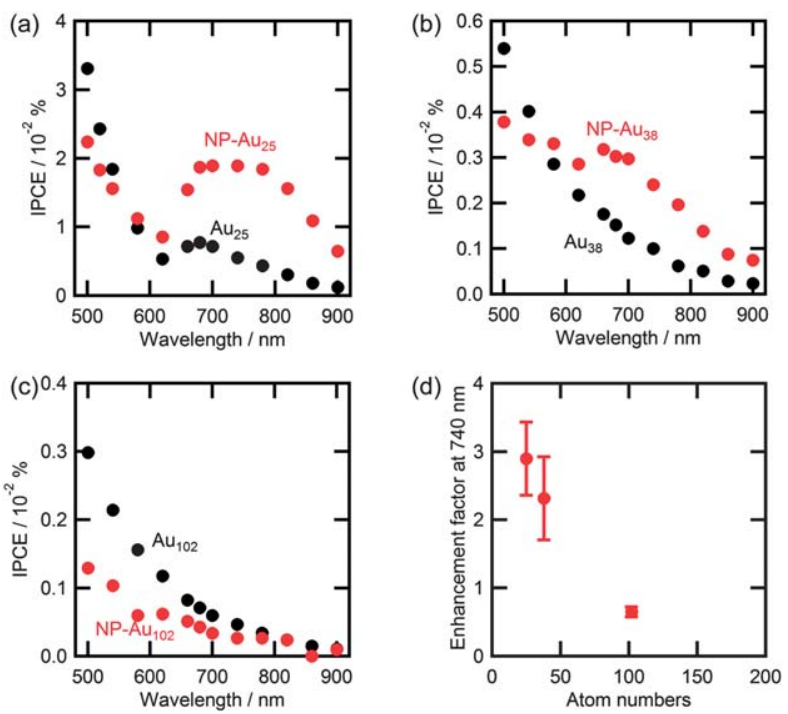

Fig. 4 Photocurrent action spectra for the ITO/Au NP/TiO $(6 \mathrm{~nm}) / \mathrm{Au} \mathrm{CL}$ and ITO/ $\mathrm{TiO}_{2}(6 \mathrm{~nm}) / \mathrm{Au} \mathrm{CL}$ electrodes in the presence of Lil: (a) $\mathrm{Au}_{25}(\mathrm{SG})_{18}$, (b) $\mathrm{Au}_{38}(\mathrm{SG})_{24}$ and (c) $\mathrm{Au}_{102}(\mathrm{SG})_{44}$. (d) Enhancement factor of photocurrents under $740 \mathrm{~nm}$ light as a function of the $\mathrm{CL}$ size. 
CdTe quantum dots to Au NPs becomes more significant as the quantum dot size increases. ${ }^{54}$

The plasmonic enhancement of Au CLs may be involved in the case of polydisperse Au NPs deposited photocatalytically or chemically on $\mathrm{TiO}_{2}$, because Au CLs may also be deposited with NPs. ${ }^{2655}$ Notably, Kominami et al. ${ }^{55}$ reported that photocatalytic $\mathrm{H}_{2}$ generation from alcohol on $\mathrm{TiO}_{2}$ modified with plasmonic $\mathrm{Au}$ NPs was improved by coexisting cluster-sized Au particles. Although their average size, $\sim 1.4 \mathrm{~nm}$, corresponds to $100 \mathrm{Au}$ atoms, CLs smaller than the average size would benefit from the plasmonic enhancement. Moreover, Kamat et al. ${ }^{56}$ suggested that the photocatalytic activity of Ag NPs was increased by CL segments at the NP surface. This can also be explained in terms of the plasmonic enhancement of the CL-sensitized process. It is also suggested that the plasmon-induced charge separation of metal $\mathrm{NP}-\mathrm{TiO}_{2}$ systems would be improved in efficiencies and functionalities by introducing CLs which effectively work as a photosensitizer as well as a catalyst.

\section{Conclusions}

In this study, we have developed Au CL-NP diad systems on $\mathrm{TiO}_{2}$ and enhanced the $\mathrm{Au}_{25}$-sensitized processes by plasmonic near field around Au NPs. The maximum enhancement factor of $\sim 9$ was reached when the CL-NP spacing was 3-10 $\mathrm{nm}$. The enhancement was also observed for $\mathrm{Au}_{38}$, but not for $\mathrm{Au}_{102}$. Thus, performances of photovoltaics and photocatalysis based on small metal CLs would be improved by plasmonic metal NPs. We also suggest that the efficiency of the plasmon-induced charge separation of NP-semiconductor systems would be enhanced by introducing appropriate metal CLs. Diad systems with metal NPs as an antenna and metal CLs as a photosensitizer/catalyst would allow development of further sophisticated photofunctional materials and devices.

\section{Acknowledgements}

This work was partly supported by "R\&D on Innovative PV Power Generation Technology" which The University of Tokyo contracted with New Energy and Industrial Technology Development Organization (NEDO) and KAKENHI (no. 22710100 for NS) from MEXT, Japan. AK thanks the JSPS Research Fellowship for Young Scientists.

\section{Notes and references}

1 M. Zhu, C. M. Aikens, F. J. Hollander, G. C. Schatz and R. Jin, J. Am. Chem. Soc., 2008, 130, 5883.

2 C. M. Aikens, J. Phys. Chem. C, 2008, 112, 19797.

3 Y. Negishi, K. Nobusada and T. Tsukuda, J. Am. Chem. Soc., 2005, 127, 5261.

4 Z. Wu, C. Gayathri, R. R. Gil and R. Jin, J. Am. Chem. Soc., 2009, 131, 6535.

5 T. Huang and R. W. Murray, J. Phys. Chem. B, 2001, 105, 12498.

6 S. Ling, A. Beeby, S. FitzGerald, M. A. El-Sayed, T. G. Schaaff and R. L. Whetten, J. Phys. Chem. B, 2002, 106, 3410.
7 G. Ramakrishna, O. Varnavski, J. Kim, D. Lee and T. Goodson, J. Am. Chem. Soc., 2008, 130, 5032.

8 Y. Zhang, X. Cui, F. Shi and Y. Deng, Chem. Rev., 2012, 112, 2467.

9 T. Inasaki and S. Kobayashi, Electrochim. Acta, 2009, 54, 4893.

10 M. Grätzel, Acc. Chem. Res., 2009, 42, 1788.

11 N. Sakai and T. Tatsuma, Adv. Mater., 2010, 22, 3185.

12 N. Sakai, T. Ikeda, T. Teranishi and T. Tatsuma, ChemPhysChem, 2011, 12, 2415.

13 A. Kogo, N. Sakai and T. Tatsuma, Nanoscale, 2012, 4, 4217. 14 A. Kogo, N. Sakai and T. Tatsuma, Electrochem. Commun., 2010, 12, 996.

15 M. J. Hostetler, J. E. Wingate, C.-J. Zhong, J. E. Harris, R. W. Vachet, M. R. Clark, J. D. Londono, S. J. Green, J. J. Stokes, G. D. Wignall, G. L. Glish, M. D. Porter, N. D. Evans and R. W. Murray, Langmuir, 1998, 14, 17.

16 P. K. Jain, K. S. Lee, I. H. El-Sayed and M. A. El-Sayed, J. Phys. Chem. B, 2006, 110, 7238.

17 P. L. Stiles, J. A. Dieringer, N. C. Shah and R. P. Van Duyne, Annu. Rev. Anal. Chem., 2008, 1, 601.

18 J. A. Schuller, E. S. Barnard, W. Cai, Y. C. Jun, J. S. White and M. L. Brongersma, Nat. Mater., 2010, 9, 193.

19 T. Torimoto, H. Horibe, T. Kameyama, K. Okazaki, S. Ikeda, M. Matsumura, A. Ishikawa and H. Ishihara, J. Phys. Chem. Lett., 2011, 2, 2057.

20 K. Awazu, M. Fujimaki, C. Rockstuhl, J. Tominaga, H. Murakami, Y. Ohki, N. Yoshida and T. Watanabe, J. Am. Chem. Soc., 2008, 130, 1676.

21 S. Linic, P. Christopher and D. B. Ingram, Nat. Mater., 2011, 10, 911.

22 P. Wang, B. Huang, Y. Dai and M.-H. Whangbo, Phys. Chem. Chem. Phys., 2012, 14, 9813.

23 C. Wen, K. Ishikawa, M. Kishima and K. Yamada, Sol. Energy Mater. Sol. Cells, 2000, 61, 339.

24 M. Ihara, M. Kanno and S. Inoue, Physica E, 2010, 42, 2867. 25 H. A. Atwater and A. Polman, Nat. Mater., 2010, 9, 205.

26 Y. Tian and T. Tatsuma, J. Am. Chem. Soc., 2005, 127, 7632. 27 Y. Tian and T. Tatsuma, Chem. Commun., 2004, 1810.

28 T. Yamaguchi, E. Kazuma, N. Sakai and T. Tatsuma, Chem. Lett., 2012, 41, 1340.

29 E. Kowalska, R. Abe and B. Ohtani, Chem. Commun., 2009, 241.

30 H. Kominami, A. Tanaka and K. Hashimoto, Chem. Commun., 2010, 46, 1287.

31 Y. Ohko, T. Tatsuma, T. Fujii, K. Naoi, C. Niwa, Y. Kubota and A. Fujishima, Nat. Mater., 2003, 2, 29.

32 E. Kazuma and T. Tatsuma, Chem. Commun., 2012, 48, 1733. 33 I. Tanabe and T. Tatsuma, Nano Lett., 2012, 12, 5418.

34 T. Tatsuma, Bull. Chem. Soc. Jpn., 2013, 86, 1.

35 T. Tatsuma, K. Takada and T. Miyazaki, Adv. Mater., 2007, 19, 1249.

36 Y. Shichibu, Y. Negishi, H. Tsunoyama, M. Kanehara, T. Teranishi and T. Tsukuda, Small, 2007, 3, 835.

37 D. Lee, R. L. Donkers, G. L. Wang, A. S. Harper and R. W. Murray, J. Am. Chem. Soc., 2004, 126, 6193.

38 D. García-Raya, R. Madueño, M. Blázquez and T. Pineda, J. Phys. Chem. C, 2009, 113, 8756. 
39 T. Tsukuda, Bull. Chem. Soc. Jpn., 2012, 85, 151.

40 K. Kimura, N. Sugimoto, S. Sato, H. Yao, Y. Negishi and T. Tsukuda, J. Phys. Chem. C, 2009, 113, 14076.

41 H. Qian, Y. Zhu and R. Jin, ACS Nano, 2009, 3, 3795.

42 H. Tsunoyama, P. Nickut, Y. Negishi, K. Al-Shamery, Y. Matsumoto and T. Tsukuda, J. Phys. Chem. C, 2007, 111, 4153.

43 H. Qian, M. Zhu, U. N. Anderson and R. Jin, J. Phys. Chem. A, 2009, 113, 4281.

44 N. K. Chaki, Y. Negishi, H. Tsunoyama, Y. Shichibu and T. Tsukuda, J. Am. Chem. Soc., 2008, 130, 8608.

45 Y. Levi-Kalisman, P. D. Jadzinsky, N. Kalisman, H. Tsunoyama, T. Tsukuda, D. A. Bushnell and R. D. Kornberg, J. Am. Chem. Soc., 2011, 133, 2976.

46 E. Hulkko, O. Lopez-Acevedo, J. Koivisto, T. Levi-Kalisman, R. D. Kornberg, M. Petterson and H. Häkkinen, J. Am. Chem. Soc., 2011, 133, 3752.

47 Y. Tachibana, K. Umekita, Y. Otsuka and S. Kuwabata, J. Phys. D: Appl. Phys., 2008, 41, 102002.
48 T. Kawawaki, Y. Takahashi and T. Tatsuma, Nanoscale, 2011, 3, 2865.

49 T. Kawawaki, Y. Takahashi and T. Tatsuma, J. Phys. Chem. C, 2013, 117, 5901.

50 S. D. Standridge, G. C. Schatz and J. T. Hupp, J. Am. Chem. Soc., 2009, 131, 8407.

51 T. Kameyama, Y. Ohno, K. Okazaki, T. Uematsu, S. Kuwabata and T. Torimoto, J. Photochem. Photobiol., A, 2011, 221, 244.

52 P. Anger, P. Bharadwaj and L. Novotny, Phys. Rev. Lett., 2006, 96, 113002.

53 O. Lopez-Acevedo, H. Tsunoyama, T. Tsukuda, H. Häkkinen and C. M. Aikens, J. Am. Chem. Soc., 2010, 132, 8210.

54 X. Zhang, C. A. Marocico, M. Lunz, V. A. Gerard, Y. K. Gun'ko, V. Lesnyak, N. Gaponik, A. S. Susha, A. L. Rogach and A. L. Bradley, ACS Nano, 2012, 6, 9283.

55 A. Tanaka, S. Sakaguchi, K. Hashimoto and H. Kominami, Catal. Sci. Technol., 2012, $2,907$.

56 W. T. Chen, Y. J. Hsu and P. V. Kamat, J. Phys. Chem. Lett., 2012, 3, 2493. 